\title{
ASPECTOS CLÍNICOS DA MÁ NUTRIÇÃO NA COVID-19
}

\author{
Adriana Aparecida de Oliveira Barbosa ${ }^{1}$ \\ Gabriel Cunha Beato ${ }^{1}$ \\ Pietra Antônia Filiol Belin² \\ Larissa Ramos Araújo ${ }^{2}$
}

\begin{abstract}
Resumo
A pandemia causada pelo novo coronavírus tem despertado discussões entre os profissionais de saúde sobre o papel da alimentação e nutrição no quadro infeccioso causado pelo vírus SARSCoV-2 em diferentes grupos populacionais. A má nutrição, que pode incluir a desnutrição e a obesidade, pode refletir em desfechos mais graves na fisiopatologia da infecção e das respostas sistêmicas causadas pela COVID-19. O presente trabalho tem como objetivo realizar considerações direcionadas ao profissional nutricionista acerca da suscetibilidade ao agravamento da COVID-19 em indivíduos submetidos à má nutrição, ressaltando possíveis desfechos da doença e a importância do cuidado nutricional na manutenção da saúde desses pacientes. Portando, manter um bom estado nutricional, aliado a um nível adequado dos micronutrientes não irá garantir proteção contra a infecção causada pela COVID-19, porém, é essencial para minimizar os riscos de agravamento dessa doença.
\end{abstract}

Palavras-chaves: COVID-19; desnutrição; obesidade; micronutrientes.

\section{Introdução}

A COVID-19, doença causada pelo vírus SARS-CoV-2, que atingiu a população mundial no final do ano de 2019, têm provocando mudanças, sociais e econômicas, desafiando os sistemas de saúde no mundo todo. Foi classificada como uma pandemia pela Organização Mundial da Saúde (OMS) em função da dimensão global de contágio (ROTHAN; BYRAREDDY, 2020; YUEN et al., 2020).

$\mathrm{O}$ vírus SARS-CoV-2 pertence à família Coronaviridae e à subfamília Orthocoronavirinae (GIWA; DESAI, 2020). Os vírus desta família são envolvidos com RNA de fita simples de sentido positivo e apresentam projeções de coroas em sua superfície, que dão a eles uma aparência de coroa quando observados em microscópio eletrônico (SINGHAL, 2020). Além do SARS-CoV-2, existem pelo menos outros seis vírus pertencentes a esta família

\footnotetext{
${ }^{1}$ Discente do Programa de Pós-Graduação em Alimentos e Nutrição, Faculdade de Ciências Farmacêuticas, Universidade Estadual Paulista "Júlio de Mesquita Filho" - UNESP, Araraquara, Brasil.

2 Discente do Curso de Graduação em Nutrição, Instituto de Biociências de Botucatu, Universidade Estadual Paulista "Júlio de Mesquita Filho" - UNESP, Botucatu, Brasil.
} 
capazes de causar doenças em humanos como, por exemplo, o SARS-CoV, responsável pelos surtos de síndrome respiratória aguda grave em 2002, e o MERS-CoV, responsável pelo surto de síndrome respiratória do Oriente Médio em 2012 (GUO et al., 2020).

Em função da ameaça à vida das pessoas e sobrecarga nos sistemas de saúde mundiais causada pela pandemia, pesquisadores do mundo todo têm buscado não só descobrir uma vacina como também encontrar mecanismos de ações mais específicos deste vírus no organismo, as medidas terapêuticas e preventivas do acelerado contágio. A alimentação é tida como uma das primeiras linhas de cuidado frente às ameaças à saúde (MONTEIRO, 2009). Neste sentido, o papel da alimentação e da nutrição no quadro infecioso pela COVID-19 vem sendo discutido no meio científico, seja na situação de agravamento do quadro clínico, onde a terapia nutricional exerce papel fundamental na recuperação de pacientes, seja no possível papel de prevenção em função dos nutrientes e do desenvolvimento de comorbidades associadas à alimentação.

Tanto a falta quanto o excesso de alimento têm interferido nos sistemas biológicos e fisiológicos tornando as pessoas mais suscetíveis às doenças (MONTEIRO, 2009). O processo de transição nutricional observado e registrado no mundo todo está ligado a uma série de transformações dos hábitos alimentares e representam grandes impactos para à saúde da população. No mundo contemporâneo, doenças relacionadas com o excesso de peso coexistem com proporções impactantes com doenças relacionadas à falta de alimentos e de uma nutrição adequada. De um lado tem-se o excesso de peso e obesidade que atinge mais de 2 bilhões de pessoas e causa quase 4 milhões de mortes anualmente em todo o mundo. Do outro, a desnutrição, presente em sua forma crônica em 815 milhões de pessoas e a deficiência de micronutrientes acometendo aproximadamente 2 bilhões de pessoas. $\mathrm{O}$ excesso de peso e a desnutrição são denominados como má nutrição e é considera atualmente a principal causa de doenças e mortes prematuras no mundo (COMISSÃO DE OBESIDADE THE LANCET, 2019).

Recentemente, pesquisadores definiram o termo "sindemia" como resultado de duas ou mais epidemias coexistentes no tempo e no espaço que produzem uma carga aumentada de doença e suas complicações na população (COMISSÃO DE OBESIDADE THE LANCET, 2019; SHIAU et al., 2020). Deste modo, a tríade obesidade, desnutrição e a COVID-19, podem ser entendidas como uma sindemia global com impactos devastadores para a saúde mundial.

O presente trabalho tem como objetivo realizar considerações direcionadas ao profissional nutricionista acerca da suscetibilidade agravamento da COVID-19 em indivíduos 
submetidos à má nutrição, ressaltando possíveis desfechos da doença e a importância do cuidado nutricional na manutenção da saúde desses pacientes.

\section{Fisiopatologia da COVID-19}

O conhecimento sobre a fisiopatologia da infecção e das respostas sistêmicas causadas pela COVID-19 não estão totalmente esclarecidas na literatura científica. Contudo, devido a sua alta semelhança com os demais vírus da família, que vêm sendo estudados desde 1966, os pesquisadores sugerem que o processo de infecção pelo vírus SARS-CoV-2 esteja associado à presença da enzima conversora da angiotensina 2 (ACE2) e também às suas caraterísticas moleculares (KANNAN et al., 2020; SOHRABI et al., 2020; VELAVAN; MEYER, 2020; ZHENG, 2020).

Sabe-se que o vírus SARS-CoV-2 é composto por grandes proteínas denominadas Proteína S (spike), Proteína E (envelope), Proteína M (membrane) e Proteínas N (nucleocapsídeo), além de várias outras proteínas acessórias (GIWA; DESAI, 2020; GUO et al., 2020). A presença destas proteínas é de extrema importância para todo o processo de infecção. A Proteína S medeia a entrada do vírus na célula ao se ligar à ACE2 presente da superfície celular do hospedeiro (FAVALLI et al., 2020; GUO et al., 2020). Não se sabe ainda quais outras moléculas e os seus papeis estão relacionadas à virulência ou que facilitam este processo, mas acredita-se que a pró-proteína convertase do tipo subtilisina chamada Furina seja a responsável pelo corte proteolítico na proteína $\mathrm{S}$ possibilitando a entrada do vírus para o interior da célula (RIZZO et al., 2020; SUN et al., 2020).

Como resposta à utilização da ECA2 pelo vírus SARS-CoV-2, ocorre uma disfunção do sistema renina-angiotensina responsável pela vasodilatação e constrição dos tecidos. $\mathrm{O}$ mecanismo proposto sugere que a regulação negativa da ECA2 causada pela infecção estimula a produção excessiva da angiotensina II que ao se ligar em seu receptor, chamado de AGTRIA, gera um aumento adicional da permeabilidade vascular e infiltração de células pulmonares, como por exemplo, macrófagos e linfócitos, e consequentemente, levando a um quadro de edema pulmonar, agravamento do processo inflamatório e danos nas células alveolares (FAVALLI et al., 2020; JIN et al., 2020; RIZZO et al., 2020; SUN et al., 2020). Apesar de a ECA2 ser amplamente expressa nas células epiteliais do trato respiratório e gastrointestinal, tornando estes os órgãos mais afetados pelo vírus, esta enzima pode ser encontrada também no 
coração, esôfago, rim, estômago, bexiga e íleo, tornando-os todos, á princípios, vulneráveis à COVID-19 (FAVALLI et al., 2020; JIN et al., 2020; STEARDO et al., 2020).

O processo em si da infecção causada pela entrada do vírus causa uma resposta imunológica por meio da ativação das células TCD4+. Essas células ativam as células B, estimulando assim a produção de anticorpos de modo a combater a infecção. Apesar desse processo ser fundamental para o combate ao vírus, ele desencadeia uma "tempestade de citocinas" e, consequentemente, imunopatogênese, que pode resultar em danos e comprometimento funcional nos tecidos pulmonares (JIN et al., 2020; LI; FAN, 2020). Esta chamada "tempestade de citocinas" resulta em um grande processo inflamatório causando ainda mais danos em vários órgãos dos pacientes infectados e já debilitados pelo vírus SARS-CoV-2 (LI; FAN, 2020; YUEN et al., 2020).

Dessa forma, tanto a alteração no sistema renina-angiotensina quanto à própria resposta imunológica causada pelo sistema imune inato geram danos nas células alveolares que podem resultar na síndrome do desconforto respiratório agudo (SDRA), caracterizada pela chegada insuficiente de oxigênio nos pulmões e na circulação, o que gera em muitos casos à necessidade da utilização da ventilação mecânica (HANFF et al., 2020).

Somado a todo processo já descrito, a infecção pelo SARS-CoV-2 pode desencadear uma resposta dependente de anticorpo mediado pelo receptor Fc (ADE) que ocorre quando esses anticorpos não são capazes de neutralizar totalmente o vírus, resultando em infecção aumentada das células-alvo estimulando a "tempestade de citocinas" e causando dano celular responsável por uma resposta inflamatória secundária (FU; CHENG; WU, 2020; JIN et al., 2020). Uma das principais causas de mortalidade nos pacientes com a COVID-19 está relacionada a um extravasamento dessas células virais para além do pulmão e a presença da ECA2 em outros órgãos. O resultado é uma resposta inflamatória sistêmica que pode causar danos de múltiplos órgãos e consequentemente a morte (FU; CHENG; WU, 2020; HANFF et al., 2020; JIN et al., 2020; LI; FAN, 2020; YUEN et al., 2020).

Diante de uma síndrome que afeta os sistemas orgânicos de defesa em múltiplos órgãos, fica evidente a importância do bom estado nutricional, se consideramos que o bom funcionamento orgânico é dependente de aportes adequados de energia e nutrientes. 


\section{Desnutrição e COVID-19}

\subsection{Fatores de risco e aumento da suscetibilidade da COVID-19}

A desnutrição apresenta como principais complicações da desnutrição a piora da resposta imunológica, atraso no processo de cicatrização, risco elevado de complicações cirúrgicas e infecciosas, maior probabilidade de desenvolvimento de lesões por pressão, aumento no tempo de internação e do risco de mortalidade com consequente aumento dos custos hospitalares (CORREIA; WAITZBERG, 2003). Crianças com desnutrição podem ter o crescimento, desenvolvimento e comportamento afetados, assim como desregulação imunológica (LARSON-NATH; GODAY, 2019).

Em se tratando de quadros clínicos da COVID-19, os pacientes infectados podem apresentar febre, tosse, dispneia, mialgia, fadiga, sintomas respiratórios e mais raramente, sintomas gastrointestinais. Nos casos de complicação, os pacientes podem desenvolver pneumonia e SDRA (SÃO PAULO, 2020).

Conforme Yeo et al. (2019), a pneumonia adquirida na comunidade é uma das principais causas de morbimortalidade e o prognóstico depende do estado nutricional prévio, principalmente nos idosos. A morte dos pacientes pela COVID-19 está relacionada principalmente com a função cardiopulmonar, devido a maior expressão de ECA2 (ZHANG et al., 2020). O estudo de Li et al. (2020), na China, mostrou que $100 \%$ dos pacientes infectados que tiveram sua morte atribuída à insuficiência respiratória, 92\% precisaram de ventilação mecânica.

A lesão pulmonar causada pelo vírus SARS-CoV-2 é caracterizada pela destruição do parênquima pulmonar e inflamação intersticial (NISHIURA et al., 2020). De acordo com a publicação da Sociedade Europeia de Nutrição Enteral e Parenteral de 2020 (BARAZZONI et al., 2020), a infecção e quadro inflamatório da COVID-19 está relacionado com a piora da desnutrição e o tempo de UTI nos pacientes contaminados.

Foi observado nos pacientes com a COVID-19, uma grave cascata inflamatória ativada e confirmados como marcadores bioquímicos específicos alterados: Proteína C Reativa marcador de inflamação; Amilóide Sérico A - transportador de lipídios na inflamação; Procalcitonina - indicador de infecção bacteriana; neutrófilos aumentados conjuntamente a linfócitos diminuídos (LI et al., 2020).

A desnutrição é associada com a piora da resposta inflamatória e a imunodeficiência, pois interfere na quantidade e função de células $\mathrm{T}$, altera a liberação de citocinas e causa 
ativação pró-inflamatória, o que predispõe às infecções e o aumento de suscetibilidade de doença infecciosas (CARBONE et al., 2016). Segundo Taylor et al. (2012), ratos infectados com influenza e com dietas pobres em proteínas tiveram vírus mais persistentes, variedade de células inflamatórias induzidas pelo vírus no pulmão e mortalidade.

Portanto, a ineficiência observada na resposta a vírus em condições de desnutrição pode estar relacionada ao desenvolvimento, ativação e proliferação alteradas de células TCD8+. As infecções virais e a resposta imune correspondente estão associadas à mortalidade significante na população e muitas vezes, por conta dos múltiplos mecanismos de resposta (adaptativa ou imune) contra o vírus, grande parte das infecções é assintomática (MACHADO et al., 2004).

\subsection{Agravamento do processo infeccioso dos indivíduos com COVID-19 em terapia intensiva}

Outro agravamento importante que está relacionado à desnutrição em pacientes com COVID-19 é a necessidade da estadia em unidades de terapia intensiva (UTI), principalmente em pacientes que necessitem do uso de respiradores artificiais nos quadros de SDRA. A permanência prolongada em UTI é associada à desnutrição, que leva a piora na qualidade de vida, incapacidade e morbimortalidade. Por isso, a prevenção, diagnóstico e tratamento da desnutrição devem ser considerados no tratamento de pacientes com a COVID-19 (BARAZZONI et al., 2020).

Em um estudo retrospectivo feito na China, com 25 pacientes que tiveram como desfecho óbito pela COVID-19, mostrou que esses pacientes tiveram concentração de albumina e hemácias diminuídas, indicando sinais de desnutrição naqueles pacientes graves infectados com o vírus (LI et al., 2020). Além disso, em outro estudo, com pacientes infectados por influenza, foi observado que a desnutrição esteve entre os fatores que tiveram relação positiva com a mortalidade (REYES et al., 2010).

Dois critérios são abordados como fator de risco para o agravamento da COVID-19, com consequente maiores taxas de mortalidade: a idade avançada e as doenças crônicas não transmissíveis (DCNT). Segundo a Organização Mundial da Saúde (2015), as DCNT causam 16 milhões de mortes prematuras, antes dos 70 anos, no mundo. São elas: doença cardiovascular, câncer, diabetes mellitus, doenças respiratórias crônicas, hipertensão arterial e doenças degenerativas. Os idosos, classificados acima de 60 anos de idade, muitas vezes possuem uma ou mais DCNT. 
Pressupõe-se que preservar estado nutricional é importante para reduzir as complicações do risco nutricional e os sintomas da COVID-19, uma vez que podem prejudicar a ingestão e absorção de alimentos (BARAZZONI et al., 2020). Para evitar a desnutrição e suas complicações nos pacientes infectados pelo vírus SARS-CoV-2, Barazzoni et al. (2020) preconizam o monitoramento desses pacientes por meio da triagem nutricional.

Dentre as ferramentas disponíveis para a triagem nutricional, pode ser utilizado o NRS2002 para pacientes infectados e se os mesmos apresentarem risco nutricional deve ser feita a Avaliação Subjetiva Global (BARAZZONI et al., 2020). Já pacientes que permanecem por mais de 48 horas na UTI, sem avaliação nutricional prévia, são considerados com risco de desnutrição (CAMPOS et al., 2020).

Ainda não se tem recomendações para uma terapia nutricional especializada nos casos da COVID-19, por isso, há a indicação de que o manejo nutricional do paciente infectado deve ser semelhante ao paciente em UTI admitido com comprometimento pulmonar (MARTINDALE et al., 2020). Segundo o Ministério da Saúde (BRASIL, 2016), é fundamental que as decisões a respeito da terapia nutricional sejam tomadas em conjunto pela equipe multiprofissional. No paciente grave, com uso de ventilação mecânica, Barazzoni et al. (2020) indicam o uso da sonda nasoenteral em posicionamento gástrico, que pode ser utilizada no posicionamento pós-pilórico se o paciente apresentar intolerância ou alto risco de aspiração. Deve-se iniciar a terapia com cautela e acompanhamento, a fim de evitar a síndrome de realimentação.

Segundo Barazzoni et al. (2020), é preciso evitar ao máximo que o paciente necessite da nutrição parenteral, devido aos riscos de infecção de cateter. Assim, é administrada somente nos casos de contra indicação da nutrição enteral: choque não controlado, instabilidade hemodinâmica, hipoxemia e acidose não controlada.

Após a extubação e saída da UTI, é percebido a presença de disfagia nos pacientes, com a limitação da ingestão via oral (BARAZZONI et al., 2020). A disfagia, quando se apresenta pela ineficácia da deglutição, pode levar o paciente a desnutrição e desidratação; já quando se apresenta pela insegurança da deglutição junto a aspirações, pode desenvolver infecções respiratórias e pneumonia aspirativa (GALLEGOS et al., 2017). Neste momento, é possível explorar os comfort foods: alimentos cujo consumo está associado ao conforto psicológico, por meio de sensação de bem-estar (SPENCE, 2017). Segundo Stein (2008), existe o interesse do uso terapêutico de alimentos de conforto para pacientes idosos, uma vez as recomendações para 
manutenção da saúde podem não estar sendo atingidas. Porém, Barazzoni et al. (2020) indicam que se a deglutição não for segura, deve ser continuado o uso da nutrição enteral nos pacientes hospitalizados.

Em se tratando de paciente em indicação de alimentação via oral, não existe recomendação específica. No estando, seguindo as boas práticas, a dieta deve levar em conta o estado geral do paciente e, por inferência, seu sistema digestório e se existe algum risco de aspiração. Sobretudo, um grande esforço deve ser feito para evitar a desnutrição intra-hospitalar e, para tanto, atenção às suas preferências alimentares do paciente deve ser dada. Dado as condições de isolamento, a comunicação com o paciente estará comprometida, muitas vezes feita por intermédio de outro profissional, mas o importante é que seja viabilizada.

\section{Obesidade e COVID-19}

De maneira fisiopatológica antagônica à desnutrição, mas de semelhante impacto na saúde, a obesidade vem sendo descrita como uma das principais condições de saúde prévias à contaminação pelo vírus SARS-CoV-2 que aumenta expressamente o risco de mortalidade destes indivíduos (KALLIGEROS et al., 2020).

\subsection{Fatores de risco relacionados à obesidade e o aumento da suscetibilidade da COVID-19}

Apesar de diversos estudos constatarem a relação direta entre o índice de massa corporal (IMC) elevado e a piora nos quadros clínicos de pacientes com a COVID-19 (KASSIR, 2020; PUIG-DOMINGO; MARAZUELA; GIUSTINA, 2020; ZHENG, 2020), pesquisas que buscam compreender a fundo os processos fisiopatológicos da obesidade e o papel decisivo na evolução da contaminação do novo coronavírus ainda não foram realizadas.

A obesidade está frequentemente associada à presença de outras comorbidades como a dislipidemia, hipertensão arterial sistêmica e diabetes do tipo 2. Todas estas comorbidades são fatores de riscos importantes no quadro de infecção causada pela COVID-19 (STEFAN et al., 2020).

Outra evidência importante, é que o agravamento da contaminação pela COVID-19 em pessoas obesas parece estar relacionado principalmente ao fato de indivíduos obesos serem considerados como "continuamente inflamados" por condições do aumento de citocinas próinflamatórias do excesso de tecido adiposo (DIETZ; SANGTOS-BURGOA, 2020). Além disso, 
o aumento da adiposidade pode prejudicar o microambiente pulmonar contribuindo para um ciclo desadaptativo de inflamação local e lesão secundária (CARTER; BARANAUSKAS; FLY, 2020). Entretanto, segundo Ryan e Caplice (2020), ainda são necessários estudos para se compreender como esta ativação ocorre.

O consumo de alimentos pró-inflamatórios ricos em gorduras saturadas, gorduras trans, açúcares simples e sal, tais como produtos altamente industrializados, frituras, carnes vermelhas e bebidas açucaradas, recorrentemente associado a hábitos de vida de pessoas obesas, também pode elevar o estado pró-inflamatório destes indivíduos e dificultar uma resposta imune mais efetiva no caso da contaminação pelo vírus SARS-Cov-2 (LEE; LEE; CHOUE, 2013; MUÑOZ; COSTA, 2013).

O consumo deste padrão alimentar é capaz de ativar o sistema imunológico inato e prejudicar a imunidade adaptativa, levando à inflamação crônica e à defesa do hospedeiro prejudicada contra o vírus. Além disso, a inflamação periférica causada pela COVID-19 pode ter consequências em longo prazo, levando a condições médicas crônicas como demência e doença neurodegenerativa provavelmente através de mecanismos neuroinflamatórios que podem ser agravados por uma dieta não saudável (BUTLER; BARRIENTOS, 2020).

\subsection{Agravamento do processo infeccioso dos indivíduos com COVID-19 em terapia intensiva}

Em 2020, Kalligeros et al. constataram que a obesidade grave (IMC $\geq 35 \mathrm{~kg} / \mathrm{m}^{2}$ ) esteve associada à admissão na UTI, enquanto a história de doença cardíaca e obesidade (IMC $\geq 30$ $\mathrm{kg} / \mathrm{m}^{2}$ ), como aumento da resistência das vis aéreas e troca gasosa prejudicada, baixa força muscular respiratória e volumes pulmonares, estiveram independentemente associadas ao uso de ventilação mecânica invasiva (STEFAN et al., 2020).

Simonnet et. al. (2020) também encontraram dados que sustentam a forte relação entre obesidade e os desfechos negativos da contaminação pela COVID-19 ao constatarem a alta prevalência de obesidade em indivíduos internados e que o agravamento da infecção aumenta de acordo com índices de massa corporal elevados. Sabe-se ainda que o excesso de massa corporal dificulta a plena função pulmonar que pode ser seriamente agravada na SDRA, aumentando significativamente a mortalidade de pessoas obesas (SIMONNET et al., 2020).

Ryan, Ravussin e Heymsfield pulicaram, em (2020), um artigo alertando sobre a contaminação pela COVID-19 e a obesidade severa e ao indicarem pontos importantes na 
relação entre elas. Em casos de internação, as intubações em indivíduos obesos são mais desafiadoras e os diagnósticos por imagem são de difícil execução e interpretação devido às limitações de equipamentos e técnicas. Além disto, problemas com o posicionamento, transporte destes indivíduos e existência de estruturas físicas adequadas e de equipamentos, como macas, tornam o cuidado do paciente obeso pela COVID-19 muito mais complicado.

$\mathrm{Na}$ ausência de protocolos específicos, pressupõe-se que o cuidado com esses pacientes hospitalizados deva seguir os protocolos existentes, guiando-se pelos sinais e sintomas e estado geral do paciente. A identificação de marcadores pró-inflamatórios e avaliação antropométrica e bioquímica desses pacientes, poderão ser determinantes para avaliação do risco de agravamento nesses pacientes e poderão ser úteis tanto em cuidados primários quanto em hospitais (STEFAN et al., 2020). Neste caso, em especial, a humanização do tratamento é fundamental, visto que existe um estigma que acompanha pessoas obesas nos serviços de saúde, com tendência dos profissionais de culpabilizar o paciente por sua condição (ALBERGA et al.; 2019).

\section{Possíveis Papeis dos Micronutrientes}

O cuidado nutricional é imprescindível para manutenção do sistema imunológico, principalmente nos indivíduos desnutridos ou obesos (BARAZZONI et al., 2020). É importante ressaltar que as vitaminas e minerais elencados a seguir têm maior relevância no quadro clínico da COVID-19, porém, um bom estado nutricional não garante proteção contra a infecção causada pelo vírus SARS-CoV-2.

\subsection{Vitamina A}

A vitamina A é um micronutriente essencial para otimização da resposta imune. Assim, manter os níveis adequados dessa vitamina pode prevenir a piora dos sintomas da COVID-19 (ZHANG; LIU, 2020).

A deficiência de vitamina A pode alterar a integridade do epitélio nos tratos respiratório e gastrointestinal, aumentando o risco de diarreia, sarampo e malária (KATONA; KATONAAPTE, 2008). Foi observado um efeito reduzido da infecção por um tipo de coronavírus (vírus da bronquite infecciosa - IBV) em galinhas alimentadas com uma dieta adequada em vitamina A (ZHANG; LIU, 2020). Além disso, foi verificado que a suplementação de vitamina A reduziu 
a morbimortalidade em diferentes doenças infeciosas, como o sarampo, a diarreia, a pneumonia relacionada ao sarampo, e a AIDS (SEMBA, 1999).

\subsection{Vitaminas do complexo $B$}

As vitaminas do complexo B atuam como cofatores de enzimas na ativação de diferentes processos metabólicos (ZHANG; LIU, 2020). Assim, é recomendado manter as concentrações dessas vitaminas em quantidades ideias para que o sistema imune não seja prejudicado.

Keil, Bowen e Marschner (2016) desenvolveram o Sistema Mirasol Pathogen Reduction Technology (PRT), um modelo de cultura de células in vitro que combinava riboflavina e luz ultravioleta. Com a aplicação do modelo verificou-se redução efetiva do coronavírus da síndrome respiratória do Oriente Médio (MERS-CoV) em produtos de plasma humano. Foi observado que o tratamento com niacina em camundongos inibiu significativamente a infiltração de neutrófilos nos pulmões durante a lesão pulmonar induzida por ventilador, mas, também levou ao desenvolvimento de hipoxemia significativa (JONES et al., 2015).

\subsection{Vitamina $\mathrm{C}$}

A vitamina $\mathrm{C}$ desempenha várias funções no organismo, sendo antioxidante, a mais conhecida. É importante ter uma ingestão regular e adequada dessa vitamina para a manutenção da saúde (HEMILÄ, 1997). Porém, são necessários mais estudos que possam esclarecer a dose suplementar da vitamina $\mathrm{C}$ em diferentes situações de risco.

Atherton, Fisher e Kratzing (1978) mostraram que a vitamina C aumentou a resistência das culturas de órgãos traqueais de embriões de frango à infecção por um coronavírus aviário. Já Hemilã (1997), analisou os seis maiores estudos de suplementação de vitamina C (> ou $=1 \mathrm{~g} / \mathrm{dia}$ ) realizados em indivíduos saudáveis de países ocidentais e constatou que a incidência de resfriado comum não foi reduzida nos grupos suplementados quando comparado aos grupos placebos. Entretanto, em estudos realizados com estudantes britânicos do sexo masculino que apresentavam baixos níveis sanguíneos de vitamina $\mathrm{C}$, foi encontrada uma redução significativa na incidência de resfriado comum nos grupos suplementados com vitamina C (HEMILÄ, 1997), mostrando que doses excessivas da vitamina não são recomendadas. 


\subsection{Vitamina D}

A vitamina D vem sendo associada ao sistema imunológico nos últimos estudos (ZHANG; LIU, 2020). Contudo, pesquisas que envolvem a suplementação dessa vitamina ainda são contraditórias. Assim, são necessárias maiores evidências sobre os níveis de vitamina D seguros à saúde.

Estudos recentes associaram a vitamina D com a redução do risco da COVID-19, em função do surto ter ocorrido no inverno, época em que as concentrações de 25-hidroxivitamina D são muito baixas, e pelas taxas de letalidade estarem aumentadas em idosos, população que possui exposição ao sol limitada (GRANT et al., 2020). Um ensaio clínico randomizado foi realizado em Atlanta, na Geórgia, com pacientes críticos sob ventilação mecânica que receberam altas doses de vitamina $\mathrm{D}$. Foi observado aumento nas concentrações plasmáticas de vitamina $\mathrm{D}$ e diminuição do tempo de internação hospitalar, sem alteração de outros resultados clínicos (HAN et al., 2016).

\subsection{Vitamina $\mathbf{E}$}

A vitamina E desempenha um papel importante na redução do estresse oxidativo por meio da inativação de radicais livres e espécies reativas de oxigênio (BATISTA; COSTA; PINHEIRO-SANT'ANA, 2007). Contudo, ainda existem controvérsias, em relação a dose suplementar dessa vitamina.

Em um estudo realizado com camundongos infectados pelo coxsackievírus miocárdico B3 (CVB3/20), foi observado que a deficiência de vitamina $\mathrm{E}$ agravou a patologia cardíaca e intensificou a virulência da infecção (BECK, 1997). Além disso, um estudo feito com bezerros de raça holandesa infectados pelo vírus da diarreia viral bovina (BVDV) relatou uma associação inversa entre as concentrações de vitamina E e D e a infecção aguda induzida pelo vírus (NONNECKE et al., 2014).

\section{6. Ácidos graxos poli-insaturados}

No grupo dos ácidos graxos poli-insaturados (AGPI) encontram-se o ômega 3 e ômega 6 (PERINI et al., 2010). A relação entre a ingestão de ambos é fundamental para o bom funcionamento do organismo. A OMS recomenda que a razão entre o ômega 6 e ômega 3 seja de 5:1 - 10:1 (MARTIN et al., 2006). A disponibilidade do ômega 3 é o fator mais importante para formação de eicosanoides anti-inflamatórios, que regulam a atividade celular e podem 
levar a uma imunossupressão e redução das respostas inflamatórias (PERINI et al., 2010). O ômega 3 deve ser considerado como uma forma de intervenção na prevenção e tratamento de algumas doenças (ZHANG; LIU, 2020). Entretanto, maiores estudos devem ser realizados a respeito da razão ideal entre ômega 3 e ômega 6 em diferentes populações.

Sabe-se que o ômega 3 é um potente mediador na resolução da inflamação, enquanto o ômega 6 promove inflamação, dor e coagulação (CAI et al., 2018). Em um estudo experimental foi observado um efeito inibitório na replicação do vírus da hepatite C (HVC) durante a terapia antiviral em pacientes japoneses, porém, não encontraram o mesmo efeito em pacientes caucasianos. Pode-se explicar essa diferença de resposta ao tratamento do HVC pelo fato dos japoneses terem hábitos alimentares que influenciam em uma absorção nutricional mais baixa de ômega 6 quando comparado a população caucasiana (CAI et al., 2018).

\subsection{Ferro}

O ferro é um mineral essencial para o organismo. A deficiência desse micronutriente é considerada um dos maiores problemas de saúde pública, e está associada a prejuízos na imunidade, reduzindo as defesas do corpo contra os patógenos (KATONA; KATONA-APTE, 2008). Assim, é necessária a implantação de políticas públicas que norteiem a nível nacional, estadual e municipal ações de combate à anemia, e que maiores evidências sejam constatadas, aprimorando o cuidado nutricional nos serviços de saúde.

Em um estudo de caso controle realizado em crianças hospitalizadas de 2 a 5 anos na Unidade Pediátrica do Hospital Universitário Anuradhapura, foi observado que as crianças anêmicas eram mais propensas a desenvolver infecções agudas do trato respiratório e gastroenterite quando comparadas às crianças não anêmicas. Entretanto, quantidades supra fisiológicas de ferro podem agravar a infecção, pois os patógenos também necessitam desse mineral para sobrevivência e replicação no hospedeiro, podendo até aumentar a patogenicidade (JAYAWEERA; REYES; JOSEPH, 2019).

\subsection{Zinco}

O zinco é um mineral essencial para a atividade de mais de 300 enzimas. A deficiência do zinco afeta as células imunológicas, modificando a resposta imune do hospedeiro, e consequentemente, aumentando o risco a infecções graves e até a morte (ZHANG; LIU, 2020). Por isso, é importante manter os níveis de zinco em quantidades recomendadas e realizar mais 
estudos que assegurem a prescrição de altas doses desse mineral no tratamento de uma variedade de doenças.

Foram encontradas baixas concentrações de zinco no sangue de pacientes com tuberculose, doença de Crohn, diarreia e pneumonia. Foi observado em estudos que a suplementação de zinco em populações com deficiência desse mineral reduziu a morbimortalidade de infecções respiratórias agudas inferiores e acelerou a recuperação de pneumonia grave (KATONA; KATONA-APTE, 2008).

Por fim, embora existam estudos contraditórios, as evidências disponíveis indicam que a manutenção dos micronutrientes em níveis adequados tem papel fundamental na modulação da resposta imunológica. O uso de quantidades supra fisiológicas ou supra terapêuticas de vitaminas e minerais, pode causar prejuízos da função imune, contribuindo para piora do quadro clinico da COVID-19. Portando, frente a estas situações os autores ressaltam a importância das orientações do Guia Alimentar para a População Brasileira na tentativa de minimizar os riscos de agravamento desta doença.

\section{Considerações Finais}

A má nutrição pode potencializar as complicações em pacientes infectados pelo vírus SARS-CoV-2. Entretanto, a inexistência, até o presente momento, de protocolos nutricionais específicos para a contaminação pelo novo coronavírus e de estudos que comprovem os mecanismos da infecção em relação aos quadros de desnutrição e obesidade, a recomendação tem sido que esses pacientes sejam cuidados observando-se protocolos genéricos, conforme o estado geral do paciente. Além disso, a suplementação de micronutrientes parece não ter efeito na melhora do quadro infeccioso, o que descarta a recomendação para suplementação nutricional. Assim, o melhor do conhecimento existente indica para um olhar cuidadoso e intuitivo do nutricionista na tomada de decisão, assim como atento ao surgimento de novos consensos, que não tardarão a surgir.

\section{Referências}

ALBERGA AS, EDACHE IY, FORHAN M, RUSSELL-MAYHEW S. Weight bias and health care utilization: a scoping review. Primary Health Care Research \& Development, 20, p.1-14. 2019.

ATHERTON, J. G.; KRATZING, C. C.; FISHER, A. E. The Effeet of Aseorbie Aeid on Inieetion of Chiek Embryo Ciliated Traeheal Organ Cultures by Coronavirus. Archives of Virology, v. 56, p. 195-199, 1978. 
BARAZZONI, R. et al. ESPEN expert statements and practical guidance for nutritional management of individuals with SARS-CoV-2 infection. Clinical Nutrition, v. 36, n. 6, p. $1934-1638,2020$.

BATISTA, E. D. S.; COSTA, A. G. V.; PINHEIRO-SANT’ANA, H. M. Adição da vitamina E aos alimentos: implicações para os alimentos e para a saúde humana. Revista de Nutrição, v. 20, n. 5, p. 525-535, 2007.

BECK, M. A. Increased Virulence of Coxsackievirus B3 in Mice Due to Vitamin E or Selenium Deficiency. The Journal of Nutrition, v. 127, n. 5, p. 966S-970S, 1997.

BRASIL. Ministério da Saúde. Secretaria de Atenção à Saúde. Departamento de Atenção Especializada e Temática. Manual de terapia nutricional na atenção especializada hospitalar no âmbito do Sistema Único de Saúde - SUS. Brasília: Ministério da Saúde, 2016.

BUTLER, M. J.; BARRIENTOS, R. M. The impact of nutrition on COVID-19 susceptibility and long-term consequences. Brain, Behavior, and Immunity, n. April, p. 0-1, 2020.

CAI, C. et al. Macrophage-Derived Extracellular Vesicles Induce Long-Lasting Immunity Against Hepatitis C Virus Which Is Blunted by Polyunsaturated Fatty Acids. Frontiers in Immunology, v. 9, p. 1-11, 2018.

CAMPOS, L. F. et al. Parecer BRASPEN/ AMIB para o Enfrentamento do COVID-19 em Pacientes Hospitalizados. Braspen J, v. 35, n. Supl 1, p. 3-5, 2020.

CARBONE, F. et al. Metabolic control of immune tolerance in health and autoimmunity. Seminars in Immunology, v. 28, n. 5, p. 491-504, 2016.

CARTER, S. J.; BARANAUSKAS, M. N.; FLY, A. D. Considerations for Obesity, Vitamin D, and Physical Activity Amid the COVID-19 Pandemic. Obesity, p. oby.22838, 21 maio 2020.

COMISSÃO DE OBESIDADE THE LANCET. A sindemia global da obesidade, desnutrição e mudanças climáticas - Relatório da Comissão The Lancet. The Lancet, 2019.

CORREIA, M. I. T. D.; WAITZBERG, D. L. The impact of malnutrition on morbidity, mortality, length of hospital stay and costs evaluated through a multivariate model analysis. Clinical Nutrition, v. 22, n. 3, p. 235-239, 2003.

DIETZ, W.; SANTOS-BURGOA, C. Obesity and its Implications for COVID-19 Mortality. Obesity, v. 28, n. 6, p. 1005-1005, 2020.

FAVALLI, E. G. et al. COVID-19 infection and rheumatoid arthritis: Faraway, so close! Autoimmunity Reviews, v. 19, n. 5, 2020.

FU, Y.; CHENG, Y.; WU, Y. Understanding SARS-CoV-2-Mediated Inflammatory Responses: From Mechanisms to Potential Therapeutic Tools. Virologica Sinica, 3 mar. 2020.

GALLEGOS, C. et al. Nutritional Aspects of Dysphagia Management. In: Advances in Food and Nutrition Research. v. 81, p. 271-318, 2017. 
GIWA, A.; DESAI, A. Novel coronavirus COVID-19: an overview for emergency clinicians. Emergency medicine practice, v. 22, n. 2, p. 1-21, 2020.

GRANT, W. B. et al. Evidence that vitamin d supplementation could reduce risk of influenza and covid-19 infections and deaths. Nutrients, v. 12, n. 4, p. 1-19, 2020.

GUO, Y. et al. The origin, transmission and clinical therapies on coronavirus disease 2019 (COVID-19) outbreak - an update on the status. Military Medical Research, v. 7, n. 1, p. 11, 13 dez. 2020.

HAN, J. E. et al. High dose Vitamin D administration in ventilated intensive care unit patients: A pilot double blind randomized controlled trial. Journal of Clinical and Translational Endocrinology, v. 4, p. 59-65, 2016.

HANFF, T. C. et al. Is There an Association Between COVID-19 Mortality and the ReninAngiotensin System - a Call for Epidemiologic Investigations. Clinical Infectious Diseases, 2020.

HEMILÄ, H. Vitamin C intake and susceptibility to pneumonia. Pediatric Infectious Disease Journal, v. 16, n. 9, p. 836-837, 1997.

JAYAWEERA, J. A. A. S.; REYES, M.; JOSEPH, A. Childhood iron deficiency anemia leads to recurrent respiratory tract infections and gastroenteritis. Scientific Reports, v. 9, n. 1, p. 1-8, 2019.

JIN, Y. et al. Virology, Epidemiology, Pathogenesis, and Control of COVID-19. Viruses, v. 12, n. 4, p. 372, 2020.

JONES, H. D. et al. Nicotinamide exacerbates hypoxemia in ventilator-induced lung injury independent of neutrophil infiltration. PLoS ONE, v. 10, n. 4, p. 1-19, 2015.

KALLIGEROS, M. et al. Association of Obesity with Disease Severity among Patients with COVID-19. Obesity, 2020.

KANNAN, S. et al. COVID-19 (Novel Coronavirus 2019) - recent trends. Eur Rev Med Pharmacol Sci, v. 24, n. 4, p. 2006-2011, 2020.

KASSIR, R. Risk of COVID-19 for patients with obesity. Obes Rev, v. 21, p, 1-2, 2020,

KATONA, P.; KATONA-APTE, J. The Interaction between Nutrition and Infection. Clinical Infectious Diseases, v. 46, n. 10, p. 1582-1588, 2008.

KEIL, S. D.; BOWEN, R.; MARSCHNER, S. Inactivation of Middle East respiratory syndrome coronavirus (MERS-CoV) in plasma products using a riboflavin-based and ultraviolet light-based photochemical treatment. Transfusion, v. 56, n. 12, p. 2948-2952, 2016.

LARSON-NATH, C.; GODAY, P. Malnutrition in Children With Chronic Disease. Nutrition in Clinical Practice, v. 34, n. 3, p. 349-358, 2019.

LEE, H.; LEE, I. S.; CHOUE, R. Obesity, inflammation and diet. Pediatric

Gastroenterology, Hepatology and Nutrition, v. 16, n. 3, p. 143-152, 2013.

LI, J.; FAN, J.-G. Characteristics and Mechanism of Liver Injury in 2019 Coronavirus

Disease. Journal of Clinical and Translational Hepatology, v. 8, n. 1, p. 1-5, 28 mar. 2020. 
LI, X. et al. Clinical characteristics of 25 death cases with COVID-19: A retrospective review of medical records in a single medical center, Wuhan, China. International Journal of Infectious Diseases, v. 94, p. 128-132, 2020.

MACHADO, P. R. L. et al. Mecanismos de resposta imune às infecções. Anais Brasileiros de Dermatologia, v. 79, n. 6, p. 647-664, 2004.

MARTIN, C. A. et al. Ácidos graxos poliinsaturados ômega-3 e ômega-6: Importância e ocorrência em alimentos. Revista de Nutricao, v. 19, n. 6, p. 761-770, 2006.

MARTINDALE, R. et al. Nutrition Therapy in the Patient with COVID-19 Disease. Society of Critical Care Medicine, 2020.

MONTEIRO, C. A. Nutrition and health. The issue is not food, nor nutrients, so much as processing. Public Health Nutrition, v. 12, n. 5, p. 729-731, 2009.

MUÑOZ, A.; COSTA, M. Nutritionally mediated oxidative stress and inflammation. Oxidative Medicine and Cellular Longevity, 2013.

NISHIURA, H. et al. The Extent of Transmission of Novel Coronavirus in Wuhan, China, 2020. Journal of Clinical Medicine, v. 9, n. 2, p. 330, 2020.

NONNECKE, B. J. et al. Acute phase response elicited by experimental bovine diarrhea virus (BVDV) infection is associated with decreased vitamin D and $\mathrm{E}$ status of vitamin-replete preruminant calves. Journal of Dairy Science, v. 97, n. 9, 2014.

ORGANIZAÇÃO MUNDIAL DE SAÚDE. Doenças crônicas não transmissíveis causam 16 milhões de mortes prematuras todos os anos. 2015. Disponível em <

https://www.paho.org/bra/index.php?option=com_content\&view=article\&id=4766:doencascronicas-nao-transmissiveis-causam-16-milhoes-de-mortes-prematuras-todos-osanos\&Itemid=839> Acesso em 17 de maio de 2020.

PERINI, J. Â. DE L. et al. Ácidos graxos poli-insaturados n-3 e n-6: Metabolismo em mamíferos e resposta imune. Revista de Nutricao, v. 23, n. 6, 2010.

PUIG-DOMINGO, M.; MARAZUELA, M.; GIUSTINA, A. COVID-19 and endocrine diseases. A statement from the European Society of Endocrinology. Endocrine, v. 68, n. 1, p. $2-5,2020$.

REYES, L. et al. Population-based surveillance for 2009 pandemic influenza A (H1N1) virus in Guatemala, 2009. Influenza and other Respiratory Viruses, v. 4, n. 3, p. 129-140, 2010.

RIZZO, P. et al. COVID-19 in the heart and the lungs: could we "Notch" the inflammatory storm? Basic research in cardiology, v. 115, n. 3, p. 31, 2020.

ROTHAN, H. A.; BYRAREDDY, S. N. The epidemiology and pathogenesis of coronavirus disease (COVID-19) outbreak. Journal of Autoimmunity, v. 109, 2020.

RYAN, D. H.; RAVUSSIN, E.; HEYMSFIELD, S. COVID 19 and the Patient with Obesity The Editors Speak Out. Obesity, v. 28, n. 5, 2020.

RYAN, P. M. D.; CAPLICE, N. M. Is Adipose Tissue a Reservoir for Viral Spread, Immune Activation and Cytokine Amplification in COVID-19. Obesity. 2020.

SÃO PAULO. Secretaria de Estado da Saúde. Orientaçãoes para a organização das ações no 
manejo do novo coronavírus (COVID-19) na atenção primária à saúde. 2020. Disponível em $<$ https://www.saude.gov.br/images/pdf/2020/marco/20/20200318-ProtocoloManejover002.pdf $>$ Acesso em 27 de maio de 2020.

SEMBA, R. D. Vitamin A and immunity to viral, bacterial and protozoan infections. Proceedings of the Nutrition Society, v. 58, n. 3, p. 719-727, 1999.

SHIAU, S. et al. The Burden of COVID-19 in People Living with HIV: A Syndemic Perspective. AIDS and Behavior, v. 1, n. 1, p. 10-18,. 2020.

SIMONNET, A. et al. High prevalence of obesity in severe acute respiratory syndrome coronavirus-2 (SARS-CoV-2) requiring invasive mechanical ventilation. Obesity, 2020.

SINGHAL, T. A Review of Coronavirus Disease-2019 (COVID-19). The Indian Journal of Pediatrics, v. 87, n. 4, p. 281-286, 2020.

SOHRABI, C. et al. World Health Organization declares global emergency: A review of the 2019 novel coronavirus (COVID-19). International Journal of Surgery, v. 76, p. 71-76, abr. 2020.

SPENCE, C. Comfort food: A review. International Journal of Gastronomy and Food Science, v. 9, n. December 2016, p. 105-109, 2017.

STEARDO, L. et al. Neuroinfection may contribute to pathophysiology and clinical manifestations of COVID-19. Acta Physiologica, 2020.

STEFAN, N. et al. Obesity and impaired metabolic health in patients with COVID-19. Nature Reviews Endocrinology, p. 4-5, 2020.

STEIN, K. Contemporary Comfort Foods: Bringing Back Old Favorites. Journal of the American Dietetic Association, v. 108, n. 3, 2008.

SUN, P. et al. Understanding of COVID-19 based on current evidence. Journal of Medical Virology, 2020.

TAYLOR, A. K. et al. Protein Energy Malnutrition Decreases Immunity and Increases Susceptibility to Influenza Infection in Mice. Journal of Infectious Diseases Advance, p. 119, 2012.

VELAVAN, T. P.; MEYER, C. G. The COVID-19 epidemic. Tropical Medicine \& International Health, v. 25, n. 3, p. 278-280, 2020.

YEO, H. J. et al. Prognostic significance of malnutrition for long-term mortality in community-acquired pneumonia: A propensity score matched analysis. Korean Journal of Internal Medicine, v. 34, n. 4, p. 841-849, 2019.

YUEN, K. et al. SARS-CoV-2 and COVID-19: The most important research questions. Cell \& Bioscience, v. 10, n. 1, p. 40, 2020.

ZHANG, H. et al. Angiotensin-converting enzyme 2 (ACE2) as a SARS-CoV-2 receptor: molecular mechanisms and potential therapeutic target. Intensive Care Medicine, v. 46, n. 4, p. $586-590,2020$.

ZHANG, L.; LIU, Y. Potential interventions for novel coronavirus in China: A systematic review. Journal of Medical Virology, v. 92, n. 5, p. 479-490, 2020. 
ZHENG, J. SARS-CoV-2: an Emerging Coronavirus that Causes a Global Threat. International journal of biological sciences, v. 16, n. 10, p. 1678-1685, 2020.

\title{
CLINICAL ASPECTS OF MALNUTRITION IN COVID-19
}

\begin{abstract}
The pandemic caused by the new coronavirus has sparked discussions among health professionals about the role of food and nutrition in the infectious condition caused by the SARS-CoV-2 virus in different population groups. Malnutrition, including obesity, may reflect more severe outcomes in the physiopathology of infection and systemic responses caused by COVID-19. The present work aims to make considerations directed to the nutritionist about the susceptibility of COVID-19 in individuals submitted to malnutrition, highlighting possible outcomes of the disease and the importance of nutritional care in maintaining the health of these patients. Therefore, maintaining a good nutritional status of these patients, combined with an adequate level of micronutrients will not guarantee protection against infection caused by COVID-19, however, it is essential to minimize the risks of worsening this disease.
\end{abstract}

Key-words: COVID-19; malnutrition; obesity; micronutrients.

\section{CLÍNICOS DE LA MALNUTRICIÓN EN LA COVID-19}

\section{Resumen}

La pandemia causada por el nuevo coronavírus ha provocado debates entre los profesionales de salud, sobre el papel de la alimentación y de la nutrición en el cuadro infeccioso causado por el virus SARS-CoV-2, en diferentes grupos poblacionales. La malnutrición, que puede incluir la desnutrición y la obesidad, puede repercutir en consecuencias más graves en la fisiopatología de la infección y de las respuestas sistémicas causadas por la COVID-19. El presente trabajo tiene como objetivo realizar consideraciones, dirigidas al profesional nutricionista, sobre la susceptibilidad al empeoramiento de la COVID-19 en individuos sometidos a la malnutrición, destacando posibles desdoblamientos de la enfermedad y la importancia del cuidado nutricional para el mantenimiento de la salud de esos pacientes. Por lo tanto, mantener un buen estado nutricional, junto a un nivel adecuado de los micronutrientes, no va a garantizar la protección contra la infección causada por la COVID-19, pero es esencial para minimizar los riesgos de empeoramiento de esta enfermedad.

Palabras clave: COVID-19; desnutrición; obesidad; micronutrientes. 